NBER WORKING PAPER SERIES

\author{
CREDIT MARKETS AND THE \\ WELFARE COSTS OF INFLATION
}

José De Gregorio

Federico Sturzenegger

Working Paper No. 4873

\author{
NATIONAL BUREAU OF ECONOMIC RESEARCH \\ 1050 Massachusetts Avenue \\ Cambridge, MA 02138 \\ October 1994
}

We thank Costas Azariadis, Valerie Bencivenga, Guillermo Calvo, Allan Drazen, Roger Farmer, Mariano Tommasi, and participants at seminars at the University of Maryland, UCLA and XII Latin American Econometric Society for many helpful comments. All remaining errors are our own responsibility. This paper is part of NBER's research program in International Finance and Macroeconomics. Any opinions expressed are those of the authors and not those of the National Bureau of Economic Research.

() 1994 by José De Gregorio and Federico Sturzenegger. All rights reserved. Short sections of text, not to exceed two paragraphs, may be quoted without explicit permission provided that full credit, including 0 notice, is given to the source. 
NBER Working Paper \#4873

October 1994

\title{
CREDIT MARKETS AND THE WELFARE COSTS OF INFLATION
}

\begin{abstract}
We construct a simple model in which high inflation imposes welfare costs because it affects the ability of the financial sector to screen between high and low cost producers. Consumers search for a low price and inflation reduces the incentives to search, resulting in an increase in the demand of high cost producers. We show that beyond a certain level of inflation there is a switch from a separating equilibrium to a pooling equilibrium, where financial institutions become unable to distinguish among clients. In this pooling equilibrium a larger share of credit is allocated to less efficient firms.
\end{abstract}

José De Gregorio

Research Department

International Monetary Fund

700 19th Street, NW

Washington, DC 20431
Federico Sturzenegger

Department of Economics

University of California

405 Hilgard Avenue Los Angeles, CA 90024-1477 and NBER 


\section{Introduction}

The purpose of this paper is to provide an analytical framework to examine how inflation may induce welfare costs through financial markets. The main reason we study the effects of inflation on the functioning of credit markets is the empirical evidence documenting a negative relationship between inflation and long-run growth. De Gregorio (1993) and Fischer (1993) have recently shown that inflation not only hampers growth by reducing investment, but also, and relatively more important, by affecting the efficiency with which investment is allocated. Indeed, De Gregorio (1993), analyzing a group of Latin American countries, shows that inflation affects growth mainly through its effects on the efficiency of investment (rather than through an effect on its level). Thus, inflation seems to have important allocative effects, and a natural candidate to produce such inefficiencies are financial markets.

We construct a stylized model in which inflation affects the ability of the financial sector to distinguish among high and low cost producers. Our model works as follows. Two types of firms play a signaling game with financial institutions. One set of firms has high productivity. The second group has lower productivity. Because firms charge different prices at low inflation, when search activity is very intense, the difference between the demands for both types of firms differ so much that low productivity firms are better off exiting the market. Production requires mimicking the high productivity type and this implies a cost in terms of overborrowing. When demand is too low the income from sales does not compensate 
for this cost. Inflation, by affecting search behavior, makes demands more similar and eventually brings the firms sufficiently close, to the point in which high cost firms have an incentive to engage in production even though this implies a cost in terms of over-borrowing. By developing a general equilibrium model we are able to discuss the welfare effects of such a switch from a separating to a pooling equilibrium where firm types cannot be distinguished any longer. We find that it reduces welfare and deteriorates the efficiency of lending. Thus, inflation implies a deterioration in welfare because it reduces the amount of information in the economy.

There are other channels through which inflation may affect the functioning of credit markets. Neumeyer (1992) develops an incomplete markets model where nominal financial instruments disappear with high (and variable) inflation, resulting in negative welfare effects. McKinnon (1991) has argued that distortions in financial markets stemming from moral hazard and adverse selection problems, generating credit rationing as that of Stiglitz and Weiss (1981), may be exacerbated in an unstable macroeconomic environment. An important mechanism is that the amount of funds that banks have available to lend may fall as inflation increases. Azariadis and Smith (1993) develop this point in a general equilibrium model and show how this may lead to incentive problems which reduce the allocative efficiency of the financial sector. Our research attempts to address the same issues as Azariadis and Smith (1993) but focuses on the allocation of credit tather than on the amount of resources available to lend. In fact, the experience of many chronic inflation economies suggests that the amount of resources intermediated by the financial system as measured by M3 or M4 remains rather stable in spite of high inflation (see Dornbusch et al 1990). Our model can account for 
a deterioration in credit quality for a given total level of intermediation.

In De Gregorio and Sturzenegger (1994) we present a partial equilibrium model in the same spirit of this paper. There, what makes firms more similar are changes in productivity. Low productivity firms also have a higher default risk. As inflation rises low productivity firms have a stronger incen tive to imitate high productivity firms in order to obtain financing at a lower interest rate. This, in turn, generates incentive problems. In this paper we focus on the revelation of information about firms' type without relying on default risk.

The paper follows in 5 sections. Section 2 describes the environment of the economy and the sequencing of transactions. Section 3 describes consumer and firm behavior with section 4 solving for the equilibrium in labor and goods markets. Section 5 introduces the financial sector while section 6 discusses welfare implications.

\section{The Environment}

The discrete time economy is populated by a large number of three period lived agents. ${ }^{1}$ We assume each generation is composed by $\mathcal{C}$ agents where $\mathcal{C}$ is a large number. Agents are endowed with one unit of labor during their first period of life. Agents differ in two dimensions. First, in the discount factor $\beta$ which we assume to be distributed with distribution function $\Phi(\beta)$. Second, agents differ in a technology characteristic: half of the agents will be born with knowledge of a technology which allows to produce with production function $X=L$. For the other half the relevant technology is $X=L / \theta$ with $\theta>1$. The preference

\footnotetext{
${ }^{1}$ The embedded search and production specification follows closely Tommasi (1994a).
} 
parameter $\beta$ is independently distributed respect to the technology so that we expect the same distribution of $\beta^{\prime}$ s among both group of agents.

During the first period of life agents do two things: they set up a firm to engage in production and sell their labor endowment in a perfectly competitive labor market. Production implies several transactions. A firm must first borrow from financial intermediaries in order to purchase the labor units required for production. After production there is matching with consumers and sales take place. At the end of the first period of life agents gather the income obtained from selling labor and whatever profits they obtained from firm activity. These resources will be used for purchases in later periods. In fact, during the second and third periods of life agents become consumers. Under certain circumstances (to be explained below) agents will have information regarding who charges which prices. In that case they match with low priced producers. In other equilibria they do not know which store charges which price, although they will know the price distribution. In this case consumers need to visit stores in order to consume, that is they have to search for a low price. In the first period they are matched with one producer. If the consumer decides not to purchase (s)he is matched with another producer one period later. Utility is linear and of the form

$$
U=C_{1}+\beta C_{2},
$$

where $C_{1}$ is consumption in the second period of life (first consumption period) and $C_{2}$ is consumption during the third period of life (second and last consumption period).

Inflation is present in the economy because the government provides a transfer in amount $T$ to each agent at the beginning of his second period of life. This 
transfer increases the nominal price level each period and generates persistent inflation.

Different markets open sequentially within a given period. Figure 1 gives a schematic representation of the transactions setup that describes the economy and is useful for the discussion below. In each period the following sequence of transactions takes place. The period starts with a set of consumers holding monetary balances which they brought from the previous period (these may be two and three period aged consumers). The government provides second period consumers with transfer $T$. This transfer is chosen to induce a given inflation rate. Next, new-born agents which hold no cash borrow from financial institutions to hire labor for production purposes. Under some conditions financial institutions will be able to distinguish between producer's types. If so, this information becomes public knowledge. Because production is non stochastic but demand depends on the search outcome after the financial market closes a set of contingent commodities markets is opened where securities conditional on the search outcome can be traded. Firms purchase and sell these securities to maximize expected profits. We show that firms use these securities to insure against the randomness of the matching process. Next, firms match with consumers. Consumers and producers when trading bargain on a price. This determines the price, quantity and profits involved in each trading. Agents, of course, consume the goods purchased. After firms sell their production, they repay their loans. Agent-firms hold these profits and labor income to be spent the following period. 


\section{Consumer and Firm Behavior}

An equilibrium is defined as a vector of prices, labor and credit allocations, and search rules such that (i) firms and financial institutions maximize expected profits, (ii) agents maximize utility and (iii) the markets for labor, credit, goods and securities all clear. In order to describe the equilibrium and how it depends on the inflation rate we discuss in turn, the search behavior of agents, the securities trading by firms and the behavior of financial intermediaries. ${ }^{2}$

\subsection{Search Behavior}

Let $I_{t}$ be the nominal income that an agent carries into period $t$ (this includes the transfer provided by the government). We will show below that in equilibrium the goods market will be characterized by a price distribution in which the high productivity producers will charge a given price $p^{h}$ and in which low productivity producers charge price $p^{l}$ with $p^{l} \geq p^{h}$. In some cases buyers may know in addition to the distribution of prices which store charges which prices. In this case they automatically match with a low cost producer solving a trivial search problem. In other cases buyers know the distribution of prices but they do not know which producers charge the low price. Once faced with a seller the consumer has to decide whether to purchase or not. Additionally, if he decides to purchase, he has to decide how much he wants to spend. This second decision is simplified by the fact that the utility function is linear, so that if he decides to purchase he will spend all of his income.

\footnotetext{
'It is well known that cash in advance economies like the one described above have many non-stationary equilibria. We concentrate in this paper uniquely on monetary stationary sleady sitates.
} 
If the seller charges $p^{h}$ then the consumer has found the low price producer, there is no point in waiting to the second period (there is discounting over time and no better deal can be attained) and the consumer spends all of his income. If the searcher finds a seller charging $p^{l}$ he has to decide whether to purchase or not. If he purchases he obtains utility $I_{t} / p_{t}^{l}$. If he rejects he will obtain an expected utility of

$$
\beta I_{t} E\left\{\frac{1}{p_{t+1}}\right\}=\beta \frac{I_{t}}{2}\left\{\frac{1}{p_{t+1}^{h}}+\frac{1}{p_{t+1}^{l}}\right\}=\beta \frac{I_{t}}{(1+\pi) 2}\left\{\frac{1}{p_{t}^{h}}+\frac{1}{p_{t}^{l}}\right\} .
$$

The return to search will depend on the expected discounted utility next period. Because firms exist in identical proportions, the probability of finding a firm of each type, next period, is $1 / 2$. Notice also that inflation, by depreciating the value of monetary balances, increases the costs of searching. Finally, that $\beta$, the discount factor, is in this specification equivalent to a search cost.

Agents will search as long as the value of searching exceeds the value of current utility. It is easy to see that there exists a unique $\hat{\beta}$, such that all agents with discount factors larger than this one will search while all others will purchase from the first store they visit. This $\hat{\beta}$ is defined by making (3.1) equal to the utility of a high price offer $I_{t} / p_{t}^{l}$. Solving for $\hat{\beta}$ we obtain:

$$
\hat{\beta}=\frac{2(1+\pi)}{\frac{p^{t}}{p^{h}}+1} .
$$

The number of searchers equals 1- $\Phi(\hat{\beta})$. Inflation leads to an increase in $\hat{\beta}$, and therefore reduces the amount of search. This will be the mechanism through which inflation will have real effects in our model. This result is similar to that in Casella and Feinstein (1990) and Tommasi (1994a). The degree of search depends also on the degree of price dispersion, a result well known in the theory of search. ${ }^{3}$

\footnotetext{
${ }^{3}$ It may appear puzzling that inflation decreases search when the opposite appears to be the
} 


\subsection{Insurance Behavior}

Firms borrow from financial intermediaries in order to purchase labor for production. Thus, firms produce a given number of units of output. Demand, on the contrary, is highly stochastic depending on the outcome of the matching process. Because firms may face any number of matches, they have an incentive to insure themselves against the randomness of the search process. Once way to do this is to trade securities with payoffs conditional on the realization of the matching process. After the matching outcome has been realized firms exercise their contingent claims, supply their consumers and then pay back the financial intermediaries.

Search is nothing but a particular realization of matches between consumers and firms. Any firm can receive any integer number of matches between 0 and $\mathcal{C}^{\prime}$ the total number of potential buyers, where $\mathcal{C}^{\prime}=\mathcal{C}+[1-\Phi(\beta)] \mathcal{C}$. In fact the search outcome is a particular point $s$ in the space $\mathcal{K}=\mathcal{C} \times \mathcal{C}^{\prime}$, which assigns to each firm $i$ an outcome of the search $N^{i}(s)$ such that $\sum_{\mathrm{i}} N^{\mathrm{i}}(s)=\mathcal{C}^{\prime}(\forall s)$, that is the sum of matches has to equal the number of consumers. ${ }^{4}$ We can define a probability function $\rho(s)$ over $\mathcal{K}$ where $\rho(s): \mathcal{K} \longrightarrow[0,1] . s$ denotes the particular draw of the distribution and indicates the number of matches each producer achieves in each draw. Because we assume that matches are independently drawn, with each firm having a probability $1 / \mathcal{C}^{\prime}$ of matching with each specific consumer, we will have empirical evidence. The proper statement is that agents choose to have less information with high inflation because the information contained in prices declines. Thus, the result that the demand for both types of firms become closer as infiation rises would hold in a more realistic setup even with the total amount of search increasing. In our context with a given price distribution this translates into lower search. See Tommasi (1994b).

${ }^{4}$ The search outcome specifies the number of matches and their type (young or old consumers), both together determine $D^{\mathrm{i}}(s)$, the firm's demand in outcome $s$. 
that $\rho(s)=\rho \forall s$ a property which will be useful below.

Consider the maximization problem faced by firm $i$. Firms maximize expected profits which equals

$$
\operatorname{Max} \sum_{\rho} p^{f}(s) \rho(s) X^{i}(s)-\left(1+r^{i}\right) \theta^{i} w \bar{X}^{i}
$$

subject to

$$
\sum_{s} p(s) X^{i}(s)=\sum p(s) \bar{X}^{i}
$$

and

$$
X^{i}(s) \leq D^{i}(s) \forall s .
$$

Where $p^{f}(s)$ denotes the sale value of the commodity in state $s . X^{i}(s)$ denotes the amount of state $s$-contingent securities firm $i$ purchases. Equation (3.2) denotes profits. The firm hires $\bar{X}^{i}$ units of labor at wage $w$. Because labor is purchased with borrowed money, an interest term $\left(1+r^{i}\right)$ is added to the labor costs. ${ }^{5}$ The amount of labor hired allows the firm to sell an equivalent amount of state contingent securities in those states in which it is productive as denoted in (3.3) and (3.4). In exchange for these it purchases a menu of state contingent commodities at price $p(s)$. It should be clear that what the state contingent claims allow firms to do is to insure amongst themselves for the randomness of the matching process. This allows the firm to satisfy demand when it is favored in the search outcome even though its production level is fixed at the beginning of the period. Finally, (3.4) indicates that the demand is only weakly constrained by the search outcome in each state $s$, so that the firm can chose not to satisfy all of its demand.

\footnotetext{
${ }^{3}$ Because firms will always make positive profits there will be no default. We assume that the cost of funds to financial institutions is zero (say because it is provided by monetary authorities at no cost) 80 that working capital will carry a gross rate of interest of 1 . Therefore, in what follows we omit the interest rate terms.
} 
The first order conditions for this problem are

$$
\begin{gathered}
\rho(s) p^{f}(s)-\lambda p(s)-\mu(s) \leq 0 \\
-\theta^{i} w+\lambda \sum s p(s)=0
\end{gathered}
$$

plus the usual complementary slackness condition for the first equation. Substituting for $\lambda$ from the second equation and realizing that $\rho(s)=\rho \forall s$, we have that

$$
\rho p^{f}(s)-\rho \theta^{i} w-\mu(s) \leq 0 .
$$

In our specification it will be the case that $p^{f}(s)>\theta^{i} w$ because final product prices are determined as a markup over costs. Therefore (3.5) implies that $\mu(s) \neq 0$, or otherwise that $X^{i}(s)=D^{i}(s) \forall s$. Because search outcomes aggregate to the same amount in each state and firms satisfy all demand, aggregate demand is not state contingent. Furthermore, because the supply of goods is also state-invariant (because it is determined by initial labor hiring) the price of both state contingent commodity and of the final product will be state independent. That is, $p^{f}(s)=p^{f}$ and $p(s)=p \forall s$. This in turn in (3.3) implies that

$$
\bar{X}^{i}=\sum_{s} \rho X(s),
$$

that is, firms hire an amount of labor sufficient to produce the expected value of sales. The firm purchases the corresponding amount of state contingent securities in order to be able to satisfy its actual demand.

\subsection{Relative Demands}

Equation (3.6) showed that firms produce the expected value of their sales. We now determine this expected demand. Not surprisingly it will depend on the 
informational restrictions under which the economy is operating. If agents can identify sellers then less productive (expensive) firms will face a zero demand $\left(X^{\prime}=0\right)$. High productivity firms will then be matched with all consumers so that each individual firm expects to sell $X^{h}=2 I_{t} / p_{t}^{h}$ units of output (because the mass of consumers is twice that of producers). In this case there will be no unrealized sales (consurners declining producers' offers) and therefore no monetary balances will be retained unspent from one period to the next.

If agents do not know the price each seller charges, deriving demands is slightly more complicated. There are now two types of consumers that each firm may face: consumers of age 2 (young consumers) and consumers of age 3 (old consumers). These consumers will purchase different amounts because their real purchasing power is different. For example, high productivity firms charging a price $p_{t}^{h}$ will sell an amount equal to $I_{t} / p_{t}^{h}$ to young consumers but only an amount $I_{t-1} / p_{t}^{h}=$ $I_{t} /\left[(1+\pi) p_{t}^{h}\right]$ to old consumers. Similarly for low productivity firms.

What remains to be determined is the number of consumers that each firms faces. There are $\mathcal{C} / 2$ firms of each type. Therefore, first period consumers are matched with probability $1 / 2$ with a high productivity producer and with probability $1 / 2$ with a low productivity firm. They will all purchase from the former group, but only a fraction $\Phi(\hat{\beta})$ (those non-searchers with sufficiently low discount factor) will purchase from the latter group. The bad-luck searchers in amount (1$\Phi(\hat{\beta})$ )/2 (searchers which were matched with low productivity firms and decided not to purchase), search again with identical matching possibilities in the following period. Because they will exit the economy after that period, they purchase independently of the search outcome. In sum the aggregate value of sales will 
equal

$$
X^{h}=\frac{I_{t}}{p_{t}^{h}}\left(1+\frac{(1-\Phi)}{2(1+\pi)}\right)
$$

for high productivity firms, and

$$
X^{\prime}=\frac{I_{t}}{p_{t}^{l}}\left(\Phi+\frac{(1-\Phi)}{2(1+\pi)}\right)
$$

for low productivity firms. Notice that relative demands differ in two dimensions. First, low productivity firms will charge a higher price and thus sell a lower amount for a given income. Secondly, the existence of price dispersion induces search, and this in turn leads to some rejections of high price offers.

\section{Equilibrium}

\subsection{Labor Market}

Labor supply is fixed and equal to one. Labor demand arises from production needs. As we will see below two potential equilibria exist. In the first, which we call a separating equilibrium, both firms reveal their type. In the other, firm types are indistinguishable and we refer to this as a pooling equilibrium.

In a separating equilibrium only high productivity firms produce. From the production technology. we know that labor demand will equal the corresponding expected level of output for each firm. Thus, in this equilibrium we require that $1=X^{h} / 2$. In short, in a separating equilibrium every high productivity firm will hire two units.

In a pooling equilibrium, by definition, all firms demand the same amount of labor. Thus, in a pooling equilibrium necessarily every firm demands one unit of labor. 


\subsection{Pricing}

When a consumer and a producer match they have to bargain about the price at which the transaction will take place. The bargaining problem becomes complicated by the existence of asymmetric information.

Consider for example the case in which the consumer makes a take-it or leaveit offer. If he knows the producer's cost, he will offer to pay the marginal cost thus driving profits to zero. If he does not know this he may choose to offer a low price if he is willing to search and a high price if he is not (if we do not allow for sequential offers). His offer, though, will never exceed the marginal cost of the high cost producer who will never obtain profits.

If firms make a take-it or leave-it offer, then it can be shown that it is impossible to sustain a price distribution. Low priced firms will always have an incentive to raise their price until they converge to that of their high cost counterpart. ${ }^{6}$

An alternative is to assume a double sided auction where both firms and consumers submit a bid, then trading if the consumer's purchase price is higher than the firm's offer price. This approach has appeal in that it leads to higher cost firms asking for higher prices (see Chaterjee and Samuelson (1983) and Fudenberg and Tirole (1991)) thus allowing for a price distribution. But the results depend heavily on the assumption of a continuous distribution in firm and consumer types, and thus breaks down in our specification. Finally, another unattractive feature is that there is multiplicity: any price can be supported as the equilibrium.

We thus simplify the analysis by considering a very simple constant markup

\footnotetext{
${ }^{6}$ This is a well know problem in search models known as the Diamond paradox. Because we require a price distribution to support a search equilibrium we need to make assumptions which insure the existence of price dispersion in equilibrium.
} 
pricing rule. Under such pricing rules we have that

$$
\begin{aligned}
& p^{l}=(1+m) \theta w \\
& p^{h}=(1+m) w .
\end{aligned}
$$

In general, we could also allow for the markups to vary with inflation, with firm type, or with the nature of the equilibrium. As long as relative price dispersion does not increase too strongly with inflation this will not affect the analysis below. ${ }^{7}$

\subsection{Demands}

We choose the numeraire to be the wage in every period. Thus, we assume $w=1$, and all nominal variables across periods must be adjusted by the steady state inflation rate.

In order to determine the relative demands we need to solve for $I_{t}$. We start with the case of perfect information (or separating equilibrium) where we have already shown that $X^{h}=2$. Substituting in the demand function $X^{h}=2 I_{t} / p_{t}^{h}$ we obtain that $I_{t}=p_{t}^{h}=(1+m)$ a result we will use below.

The case in which firm types are not identified is slightly more complicated because the working capital that firms request from financial institutions does not coincide with actual production needs. We assume, unconventionally, that all excess labor is allocated equally to those firms with excess demand. This

\footnotetext{
${ }^{7}$ It is unlikely that fully specifying the bargaining setup which renders the pricing equations (4.1) and (4.2) will change the results. For this to be the case inflation should increase price dispersion. But, if inflation increases the monopoly power of firms, it will also make the goods market closer to the Diamond world in which all prices converge to the monopoly price. Because this would concentrate the price distribution it would only reinforce the effects of inflation on search which are essential for the model. An exception is Bènabou (1988).
} 
assumption ensures that all labor is used and that each firm can satisfy its expected demand for commodities. ${ }^{8}$ Under this assumption the labor market equilibrium condition equals

$$
1=\frac{1}{2} \frac{I_{t}}{p_{t}^{h}}\left(1+\frac{(1-\Phi)}{2(1+\pi)}\right)+\frac{\theta}{2} \frac{I_{t}}{p_{t}^{l}}\left(\Phi+\frac{(1-\Phi)}{2(1+\pi)}\right)
$$

where we have used the fact that low productivity firms request $\theta$ units of labor to produce each unit of output. We use equation (4.3) to solve for the level of nominal income. We then substitute back into the demand functions to obtain the demands as function of the economic fundamentals:

$$
X^{h}=2\left(1+\frac{\left(\Phi+\frac{(1-\Phi)}{2(1+\pi)}\right)}{\left(1+\frac{(1-\Phi)}{2(1+\pi)}\right)}\right)^{-1}=2(1+\phi(\pi))^{-1}
$$

and

$$
X^{l}=2 \theta\left(1+\frac{\left(1+\frac{(1-\Phi)}{2(1+\pi)}\right)}{\left(\Phi+\frac{(1-\Phi)}{2(1+\pi)}\right)}\right)^{-1}=2 \theta\left(1+\frac{1}{\phi(\pi)}\right)^{-1}
$$

where we have introduced the notation $\phi(\pi)=\left(\Phi+\frac{(1-\Phi)}{2(1+\pi)}\right) /\left(1+\frac{(1-\Phi)}{2(1+\pi)}\right)$, to simplify the expressions. It is easy to show that $\phi^{\prime}>0$ which is an important result for the ensuing discussion.

Figure 2 shows that relative demands as a function of inflation. We add a subscript $s$ to indicate the demands in the separating equilibrium. Notice that these are independent of inflation and fully concentrated on high productivity producers. We denote with a subscript $p$ the alternative pooling equilibrium. Notice

${ }^{8}$ We allow for this transfer to take place to concentrate on the allocative effects of inflation, rather than adding a supply constraint to the effects of inflation. While plausible that efficient firms may become credit constrained at high inflation rates, we want to concentrate here on how inflation affects the efficiency of lending. This transfer effectively eliminates this supply effect. Introducing it would only reinforce the welfare results highlighted in the paper. 
that in this case there is a shift in demand towards low productivity producers and that the problem becomes worse as inflation deteriorates: inflation increases the demand of low productivity firms by reducing the incentives to search.

The above set of equations fully determine the real and nominal equilibrium given the information revealed by the financial sector. We discuss this next.

\section{The Financial Sector}

While during the contingent claims market session firms are properly identified (they are trading claims contingent on how many units of production they will sell) they are not identified by type when borrowing for working capital from financial institutions.

Because there is no default, perfectly competitive financial intermediation implies that firm's will be charged the cost of capital which we have assumed to be zero. The important role played by financial institutions is to distinguish firms types. We assume that if the financial sector can discriminate between firms, this information becomes public knowledge. If the financial sector cannot discriminate, consumers learn the characteristics of the firm after matching occurs.

The thrust of our model is to show that the financial sector can distinguish firm types only at low inflation rates. Low productivity firms always want to borrow a smaller amount because they have lower expected sales but they cannot afford to be identified as low productivity firms because they would then face no demand. While inflation is low it is too costly for low productivity firms to try to appear as high productivity firms. Thus, they stay out of the market. Inflation, nevertheless, changes relative demands, making both types of firms more similar. 
This reduces the cost of mimicking the high productivity firm. Beyond some level of inflation they enter into production. At that point the economy moves to a pooling equilibrium. The purpose of this section is to characterize the inflation rates at which this change in the nature of the equilibrium in the credit market take place.

The setup is that of a signaling game. A Perfect Bayesian equilibrium (PBE) is one equilibrium concept which can be used to characterize the solution to such a game. This requires specifying belief about firm's types for financial institutions. The argument for such belief functions will be the signals provided by firms, in our setup, their demands for credit. There are two possible equilibria. In one, a separating equilibrium, only high productivity firms produce. As we have already seen, in this equilibrium, firms hire two units of labor each. The PBE requires that in equilibrium beliefs be correct. Thus, in a separating equilibrium financial institutions believe that they are facing a high productivity producer. A second equilibrium is a pooling equilibrium where both type of firms request credit to purchase one unit of labor. The PBE requires that in this equilibrium financial institutions believe that with probability $1 / 2$ the firm is of the low productivity type. We also need to specify beliefs for off-the-equilibrium paths. For simplicity of presentation we assume that for all other borrowing amounts the financial sector believes the firm is of low productivity. ${ }^{9}$

In order to analyze the equilibria we consider a low productivity firm which is

\footnotetext{
${ }^{9}$ While a-priori it may seem reasonable to assume that if a firm demands a larger amount of credit it must be of higher productivity, this is not the case in our specification. In fact, if financial institutions were to believe that only high productivity firms would deviate in such a way, all firms would have the incentive to request this larger amount.
} 
evaluating whether to deviate from a pooling equilibrium. Sales are $X_{p}^{h}$ and $X_{p}^{l}$ but borrowing equals one unit. If

$$
p_{p}^{l} X_{p}^{l}-1 \geq 0
$$

then low productivity firms do not want to deviate from the pooling equilibrium. The profit has to be equal or greater than zero because that is the reservation value that the firm can earn if it doesn't produce. When income more than compensates having to over-borrow in amount $1-\theta X_{p}^{l}$, then the low productivity firms have an incentive to produce. We now discuss how this condition depends on the inflation rate.

Proposition 1: There exists an inflation rate $\bar{\pi}$ such that for inflation rates lower than $\bar{\pi}$ there is no incentive to pool.

Proof: Substitute (4.1) and (4.5) in (5.1) to obtain

$$
2(1+m) \geq 1+\frac{1}{\phi(\pi)} .
$$

Because the left hand side is constant and the right hand side is decreasing in the inflation rate, if it exists, a unique rate satisfies the equation with equality. Because for $\pi=0$ the lowest value for $\phi$ is $1 / 3$, a positive $\bar{\pi}$ will always exist as long as $m<1$. Otherwise, if $m>1, \bar{\pi}=0$.

In other words there is a larger incentive to pool at higher inflation rates. The intuition for this result is straightforward, at high inflation rates both firms face similar demands, therefore the excess lending required to mimic high productivity firms becomes less costly. Notice that no deviation, for either firm, is optimal 
because the financial sector would believe the firm is of the low productivity type and the firm would then have no customers. In particular, for inflation rate $\bar{\pi}$ (or any lower rate) low productivity firms do not have an incentive to ask for two units (rather than one) as this would increase their excess lending costs without any other compensating gain. The condition to be willing to borrow two units is that

$$
1+m \geq 1+\frac{1}{\phi(\pi)}
$$

which is more stringent than (5.2).Thus, when they engage in production, low productivity firms will choose to demand one unit, thus forcing high productivity firms to follow. Therefore, for inflation rates above $\bar{\pi}$ the pooling equilibrium is the unique equilibrium.

For inflation rates below $\bar{\pi}$ low productivity firms do not produce. Then high productivity firms can safely request two units of labor and the separating equilibrium prevails. Only once low productivity firms engage in production have high productivity firms to revert to the pooling equilibrium. ${ }^{10}$

${ }^{10}$ While a PBE does not restrict the beliefs off the equilibrium it is true that our specification tends to make the pooling equilibrium a likely equilibrium. The reader can rework our the specification under other of the equilibrium beliefs, or imposing additional refinements on the PBE. In general the conclusion will be that a separating equilibrium can also be supported even for inflation rates larger than $\overline{\bar{\pi}}$ so that under these alternative configurations none of the informational problems discussed in the paper arise. Thus, we believe the specification used in the paper is the interesting one. 


\section{GNP and Welfare}

Having fully characterized the equilibria we can now proceed to the discussion of welfare. Inflation has two effects in this model. First, it affects search and therefore relative demands. In fact, because it increases the relative demand for less productive firms there is a presumption that it will decrease welfare. Secondly, it affects the nature of the financial sector equilibrium thus having additional welfare effects. In this section we first compute GNP and total credit as functions of inflation. We then move to a discussion of welfare.

\subsection{GNP and Total Credit}

Denote GNP per capita by $y$. In the separating equilibrium $y^{s}=\frac{1}{2} X^{h}=1$, as all demand is concentrated in the high productivity firms. The value of GNP also follows from that fact that total labor supply equals one and all production takes place in firms with unit labor requirements.

The situation is certainly different when we consider a pooling equilibrium. In this case output per-capita equals

$$
y^{p}=\frac{X^{h}}{2}+\frac{X^{l}}{2}=\frac{1}{(1+\phi(\pi))}+\frac{1}{\theta\left(1+\frac{1}{\phi(\pi)}\right)}<1 .
$$

To show the last inequality multiply both sides by $(1+\phi(\pi))$ to obtain

$$
1+\frac{(1+\phi(\pi))}{\theta\left(1+\frac{1}{\phi(\pi)}\right)}<1+\phi(\pi) \Rightarrow 1+\phi(\pi)<\theta(1+\phi(\pi))
$$

which is true because $\theta>1$. A shift to a pooling equilibrium reduces output because it shifts production towards low productivity firms. This reduces the amount of goods which can be produced with a given amount of labor. 
Once in a poling equilibrium it is easy to show that higher inflation implies lower output. Differentiating (6.1) respect to inflation we obtain that

$$
\operatorname{sgn}\left[\frac{d y^{p}}{d \pi}\right]=\operatorname{sgn}\left[\frac{-1}{\left(1+\frac{\phi(\pi)}{\theta}\right)^{2}}+\frac{1}{\frac{\phi(\pi)^{2}}{\theta}\left(1+\frac{\theta}{\phi(\pi)}\right)^{2}}\right]<0 .
$$

This result is also intuitive: an increase in inflation shifts the relative demand towards low productivity firms because agents decide to search less. Thus, once in the pooling equilibrium additional inflation aggravates the fall in output.

Figure 3 shows how output depends on inflation in our specification. ${ }^{11}$ Initially inflation has no effect, but eventually inflation reaches $\bar{\pi}$ and the financial sector shifts to a pooling equilibrium. At that point there is a discrete fall in output. Beyond this initial jump, GNP decreases smoothly in the inflation rate.

The model also implies that the total amount of credit does not change with the inflation rate. In the separating equilibrium the total amount of credit requested equals 1 (half of the firms ask for two units) and in the pooling equilibrium it remains equal to one (all firms demand one unit). However the model predicts a deterioration in the efficiency of credit allocation.

\subsection{Welfare}

Consider the separating equilibrium. In this equilibrium we have shown that $p=I=(1+m)$. Agents endowed with technologies $X=L / \theta$ will not produce and will earn only labor income. Every agent receives a transfer of value $T$. Thus their utility equals $(1+T) /[(1+m)(1+\pi)]$. Agents with technology $X=L$ will

\footnotetext{
${ }^{11}$ We will see in the next section that the level of output is directly related to a measure of ex-ante welfare.
} 
also run firms. Thus, their consumption level equals $[1+T+2 m] /[(1+m)(1+\pi)]$, which takes into account the income from labor and from profits.

In order to compute utility we must solve for the value of the transfer. In order to do so we use the fact that aggregate spending should equal aggregate income or

$$
\frac{1}{2}\left[\frac{1+T}{(1+m)(1+\pi)}\right]+\frac{1}{2}\left[\frac{1+2 m+T}{(1+m)(1+\pi)}\right]=1 .
$$

Equation (6.2) implies that $T=(1+m) \pi$. Thus solving for the utility of both agents we have that the utility of a high cost agent is

$$
U^{\prime}=\frac{1+\pi(1+m)}{(1+m)(1+\pi)}=1-\frac{m}{(1+m)(1+\pi)}
$$

and the utility of the low cost agent is

$$
U^{h}=\frac{1+\pi(1+m)+2 m}{(1+m)(1+\pi)}=1+\frac{m}{(1+m)(1+\pi)} .
$$

Notice that the ex-ante utility equals 1 , the level of output. Interestingly, the model predicts that it is firms that lose from inflation because their profits are washed out by monetary erosion.

In a pooling equilibrium the situation is more involved because we now have to distinguish between searchers and non-searchers. The appendix shows that the ex-ante utility for an agent is again equal to the value of output which has already been shown to fall in this equilibrium. It can also be shown that the required transfer in order to generate inflation rate $\pi$ solves

$$
(1+\pi)=\frac{2 T+1+2 m y^{p}}{y^{p}} E\left\{\frac{1}{p}\right\}
$$

where $p$ denotes the expected price that an individual may expected to pay before knowing any of his characteristics. Thus, from (6.3) the rate of inflation increases with the level of the transfer and falls with the level of income. 


\section{Concluding Remarks}

We conclude by observing that in our setup there exists a range of low inflations for which there are no welfare costs. It is usually argued that it is difficult to achieve the political consensus to eliminate positive but low inflation rates. Our model provides a potential explanation for this fact: low inflation rates do not matter. The model indicates that welfare decreases monotonically but not continuously with inflation rates. There exists a threshold only beyond which inflation becomes important.

The model captures the deterioration in the efficiency of credit indicators which we believe characterizes high inflation economies. If we were to endogenize savings decisions the deterioration in the quality of credit would decrease the returns to savings and thus induce a decline in the total amount intermediated. In fact, one of the most visible effects of a successful stabilization program is the reemergence of credit to the private sector. In a companion paper, (De Gregorio, Sturzenegger (1994)) we develop a partial equilibrium model in the spirit of this paper which allows for additional comparative static exercises. In that model, the deterioration in the quality of borrowing induces a fall in total credit and an increase in real lending rates. However, regardless of the specification, we show that high inflation implies that the economy is operating with less information, less efficiently, and thus experiencing welfare losses.

Finally, this paper complements the mechanisms studied by Azariadis and Smith (1993) who discuss savings decisions and how inflation affects the volume of resources intermediated. Our approach, in contrast, stresses the quality of credit allocation. 


\section{Appendix}

Ex-ante the individual does not know whether he will be searcher or not, nor whether he will be high or low productivity. Denote

$$
E\left(\frac{1}{p_{n s}}\right)=\frac{1}{2 p_{r}}+\frac{1}{2 p_{n}}
$$

the expected price for non searchers. Denote

$$
E\left(\frac{1}{p_{s}}\right)=\frac{1}{2 p_{r}}+\frac{1}{2}\left\{\frac{1}{2(1+\pi) p_{r}}+\frac{1}{2(1+\pi) p_{n}}\right\}
$$

the expected price for searchers. Then, with probability $\Phi(\hat{\beta})$, the agent will be a non-searcher and his expected utility will equal

$$
\frac{1}{2} \frac{1+m X^{h}+T}{(1+\pi)} E\left(\frac{1}{p_{n s}}\right)+\frac{1}{2} \frac{1+m X^{l}+T}{(1+\pi)} E\left(\frac{1}{p_{n s}}\right) .
$$

Similarly, for searchers in amount $(1-\Phi(\hat{\beta}))$, we have that

$$
\frac{1}{2} \frac{1+m X^{h}+T}{(1+\pi)} E\left(\frac{1}{p_{s}}\right)+\frac{1}{2} \frac{1+m X^{l}+T}{(1+\pi)} E\left(\frac{1}{p_{s}}\right)
$$

Both (8.1) and (8.2) indicate total spending for both types. Thus, making spending equal to income and using the labor market condition which implies that $2 y^{p}=X^{h}+X^{l}$ from (6.1) we have that

$$
y^{p}(1+\pi)=\left(1+2 m y^{p}+2 T\right)\left\{\Phi(\hat{\beta}) E\left(\frac{1}{p_{n s}}\right)+(1-\Phi(\hat{\beta})) E\left(\frac{1}{p_{s}}\right)\right\}
$$

which gives equation (6.3) in the text, where $1 / p$ stands for the term in braces.

Finally substitute $\left(1+2 m y^{p}+2 T\right)$ from (8.3) in the sum of (8.1) and (8.2) to obtain that expected utility $E u$ equals

$$
E u=\frac{\Phi(\hat{\beta}) y^{p} E\left(\frac{1}{p_{n}}\right)}{\Phi(\hat{\beta}) E\left(\frac{1}{p_{n}}\right)+(1-\Phi(\hat{\beta})) E\left(\frac{1}{p_{s}}\right)}+\frac{(1-\Phi(\hat{\beta})) y^{p} E\left(\frac{1}{p_{s}}\right)}{\Phi(\hat{\beta}) E\left(\frac{1}{p_{n}}\right)+(1-\Phi(\hat{\beta})) E\left(\frac{1}{p_{s}}\right)}=y^{p},
$$

that is, that once again, expected utility equals income. 


\section{References}

[1] Azariadis, Costas and Bruce Smith (1993) "Private Information, Money and Growth," Mimeo UCLA.

[2] Bènabou, Roland (1988) "Search, Price Setting and Inflation" Review of Economic Studies, 55, pp. 353-376.

[3] Casella, Alessandra and Jonathan Feinstein (1990) "Economic Exchange During Hyperinflation." Journal of Political Economy, Vol. 98, p. 1-27.

[4] Chaterjee, Kalyan and William Samuelson (1983) "Bargaining under Incomplete Information," Operations Research, Vol. 31(5), pp. 835-851.

[5] De Gregorio, José (1993) "Inflation, Taxation, and Long-Run Growth," Journal of Monetary Economics, Vol. 31, pp. 271-298.

[6] De Gregorio, Jose and Federico Sturzenegger (1994) "Financial Markets and Inflation under Imperfect Information", IMF Working Paper WP/94/63.

[7] Dornbusch, Rudiger, Federico Sturzenegger and Holger Wolf (1990), "Extreme Inflation: Dynamics and Stabilization, Brookings Papers on Economic Activity, 2, pp. 1-83.

[8] Fischer, Stanley (1993) "The Role of Macroeconomic Factors," Journal of Monetary Economics, Vol. 32, pp. 485-512.

[9] Fudenberg, Drew and Jean Tirole (1991) Game Theory, Cambridge, MIT Press. 
[10] Mckinnon, R. (1991) The order of Economic Liberalization: Financial Control in the Transition Economy, Baltimore: Johns Hopkins University.

[11] Neumeyer, Andy (1992) "On Monetary Policy in Economies with Incomplete Asset Markets", Ph.D. Dissertation, Columbia University.

[12] Stiglitz Joseph and Andy Weiss (1981) Credit Rationing in Markets with Imperfect Information, American Economic Review, Vol 71, pp. 393-410.

[13] Tommasi, Mariano (1994), "High-Inflation: Resource Misallocations and Growth Effects", Mimeo UCLA.

[14] Tommasi, Mariano (1994), "The Welfare Effects of Inflation: The Consequences of Price Instability on Search Markets" American Economic Review, August. 
Figure 1: Timing and Structure of Transactions

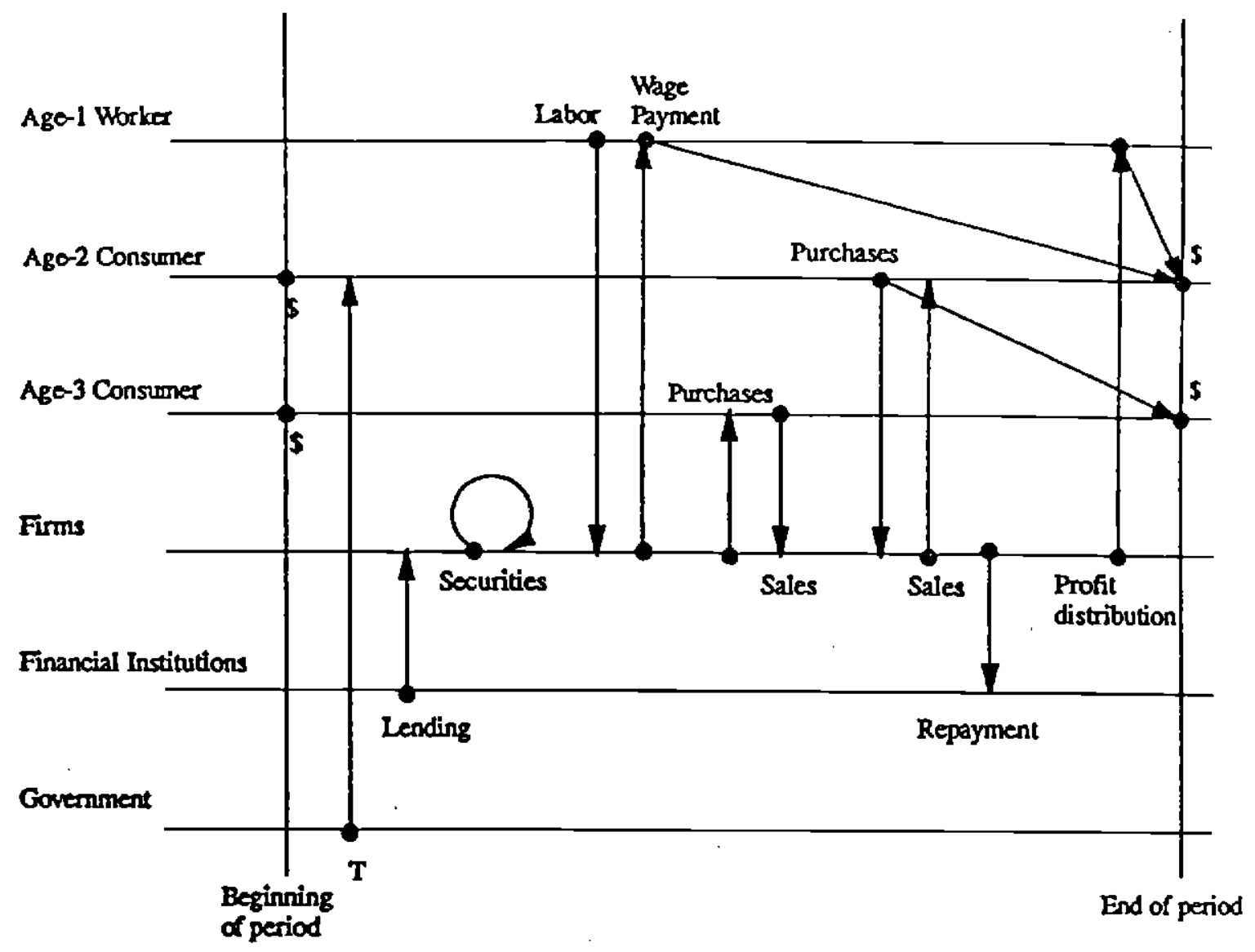


Figure 2: Demands

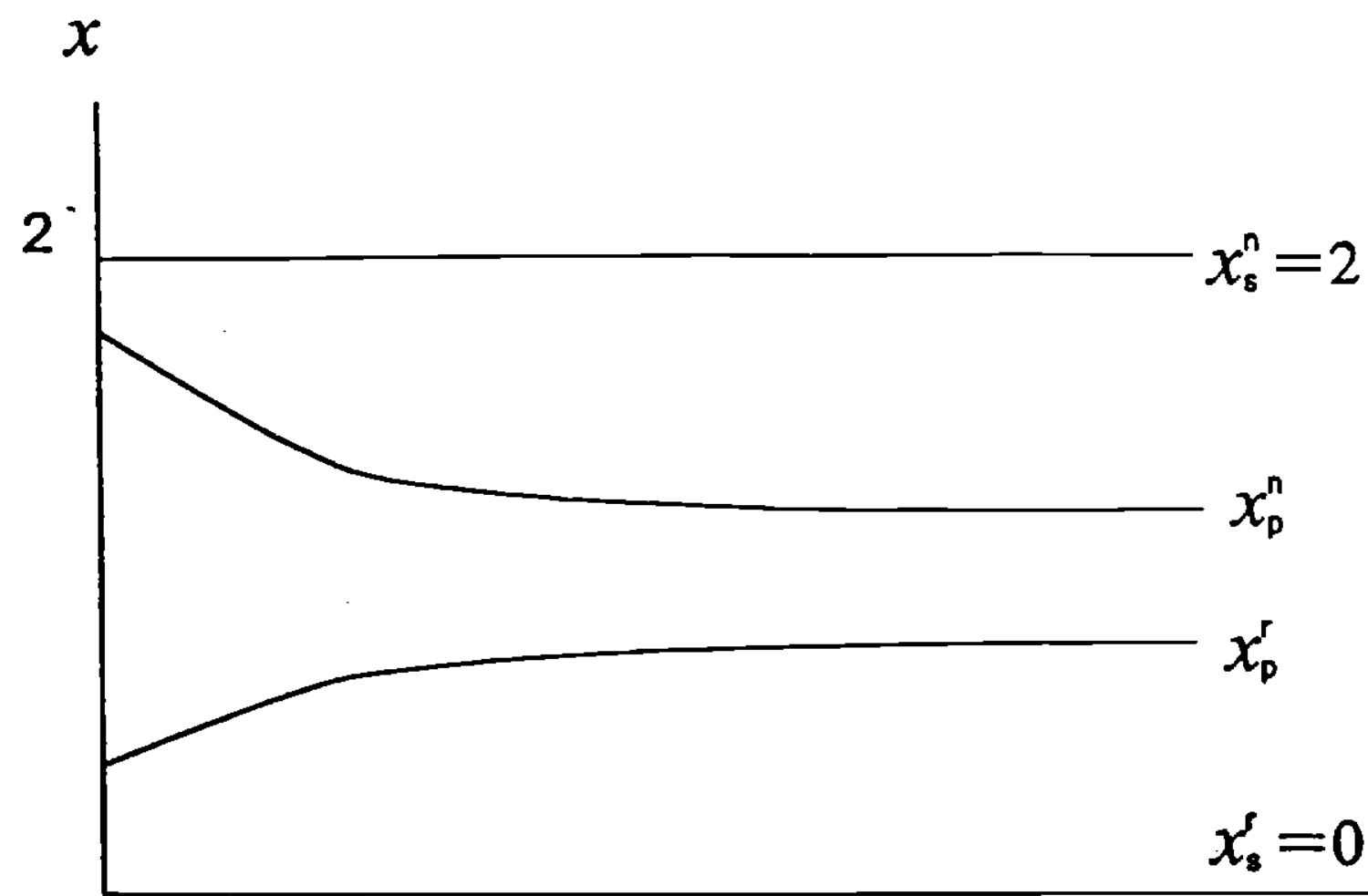


Figure 3: GNP and Inflation

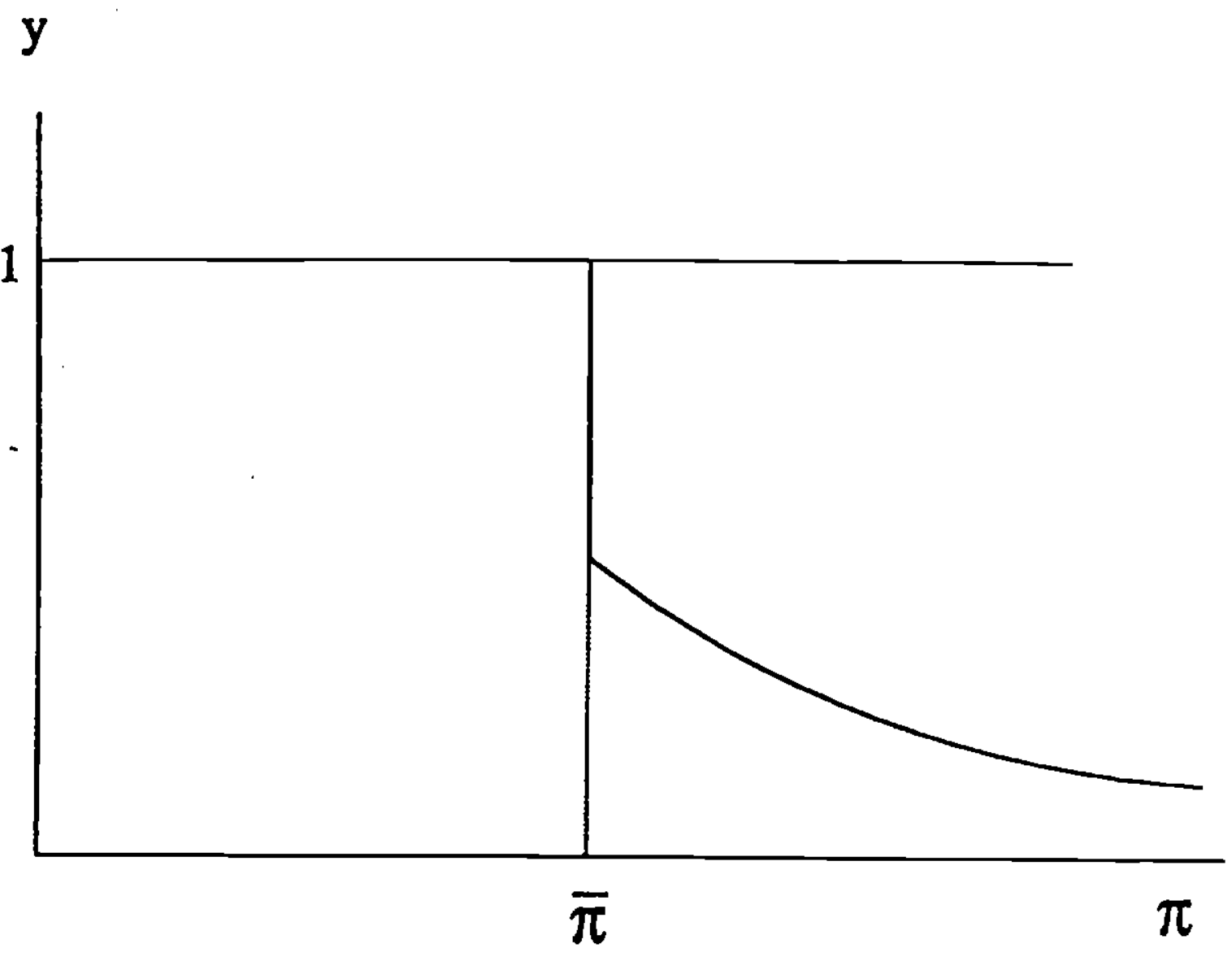

